\title{
Inter-comparison of ammonia fluxes obtained using the Relaxed Eddy Accumulation technique
}

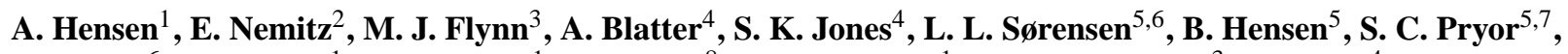 \\ B. Jensen ${ }^{6}$, R. P. Otjes ${ }^{1}$, J. Cobussen ${ }^{1}$, B. Loubet ${ }^{8}$, J. W. Erisman ${ }^{1}$, M. W. Gallagher ${ }^{3}$, A. Neftel ${ }^{4}$, and M. A. Sutton ${ }^{2}$ \\ ${ }^{1}$ Energy research Centre of the Netherlands (ECN), Petten, The Netherlands \\ ${ }^{2}$ Centre for Ecology and Hydrology (CEH), Edinburgh, UK \\ ${ }^{3}$ University of Manchester, Centre for Atmospheric Science, Manchester, UK \\ ${ }^{4}$ Agroscope Reckenholz-Tänikon Research Station ART, Zürich, Switzerland \\ ${ }^{5}$ RISOE National Laboratory, Roskilde, Denmark \\ ${ }^{6}$ National Environmental Research Institute, Roskilde, Denmark \\ ${ }^{7}$ Indiana University, Bloomington, Indiana, USA \\ ${ }^{8}$ Institut National de la Recherche Agronomique (INRA), Thiverval-Grignon, France
}

Received: 21 July 2008 - Published in Biogeosciences Discuss.: 6 October 2008

Revised: 15 September 2009 - Accepted: 16 September 2009 - Published: 16 November 2009

\begin{abstract}
The exchange of Ammonia $\left(\mathrm{NH}_{3}\right)$ between grassland and the atmosphere was determined using Relaxed Eddy Accumulation (REA) measurements. The use of REA is of special interest for $\mathrm{NH}_{3}$, since the determination of fluxes at one height permits multiple systems to be deployed to quantify vertical flux divergence (either due to effects of chemical production or advection). During the Braunschweig integrated experiment four different continuous-sampling REA systems were operated during a period of about 10 days and were compared against a reference provided by independent application of the Aerodynamic Gradient Method (AGM). The experiment covered episodes before and after both cutting and fertilizing and provided a wide range of fluxes $-60-3600 \mathrm{ng} \mathrm{NH}_{3} \mathrm{~m}^{-2} \mathrm{~s}^{-1}$ for testing the REA systems. The REA systems showed moderate to good correlation with the AGM estimates, with $r^{2}$ values for the linear regressions between 0.3 and 0.82 . For the period immediately after fertilization, the REA systems showed average fluxes $20 \%$ to $70 \%$ lower than the reference. At periods with low fluxes REA and AGM can agree within a few \%. Overall, the results show that the continuous REA technique can now be used to measure $\mathrm{NH}_{3}$ surface exchange fluxes. While REA requires greater analytical precision in $\mathrm{NH}_{3}$ measurement than the AGM, a key advantage of REA is that reference sampling periods can be introduced to remove bias
\end{abstract}

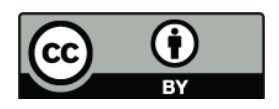

Correspondence to: A. Hensen (hensen@ecn.nl) between sampling inlets. However, while the data here indicate differences consistent with advection effects, significant improvements in sampling precision are essential to allow robust determination of flux divergence in future studies. Wet chemical techniques will be developed further since they use the adsorptive and reactive properties of $\mathrm{NH}_{3}$ that impedes development of cheaper optical systems.

\section{Introduction}

Eddy covariance (EC) measurement of trace gas fluxes is becoming more and more popular, and is in principle preferred to gradient methods due to the fundamental robustness and lack of empiricism in the EC approach. For $\mathrm{CO}_{2}, \mathrm{H}_{2} \mathrm{O}, \mathrm{N}_{2} \mathrm{O}$, $\mathrm{CH}_{4}$ and $\mathrm{O}_{3}$, for example, fast sensors are available that enable EC flux measurements (Moncrieff et al., 1997; Pattey et al., 2006; Mészáros et al., 2009). For a number of trace gases, however, such as ammonia $\left(\mathrm{NH}_{3}\right)$, sensors that can provide concentrations at the required sampling rates of above $1 \mathrm{~Hz}$ and with sufficient detection limit $\left(<0.1 \mu \mathrm{g} \mathrm{m}^{-3}\right.$ for $\left.\mathrm{NH}_{3}\right)$ are becoming available but remain expensive (Shaw et al., 1998; Fehsenfeld et al., 2002; Famulari et al., 2004; Whitehead et al., 2008). Especially for these components, the Relaxed Eddy Accumulation (REA) technique (Businger and Oncley, 1990; Zhu et al., 2000) can provide a means to determine vertical fluxes without requiring the measurement of vertical concentration profiles. Just like the EC technique,

Published by Copernicus Publications on behalf of the European Geosciences Union. 
REA does not require the stability corrections that are needed for the aerodynamic gradient method (AGM), although it still relies on an empirical parameterization. In addition, as with EC, REA derives the vertical flux from measurements at a single height above the surface. This avoids the potential errors in gradient methods arising from the fact that the flux-footprint (e.g. Korman and Meixner, 2001) is different at different heights. Flux measurement at one height also has the advantage that REA measurements at several heights could theoretically be used to investigate the potential for divergence in the vertical flux, occurring for example due to chemical production/consumption in the surface layer or due to advection from nearby sources. These issues are of topical interest for $\mathrm{NH}_{3}$ (Sutton et al., 2001), with the REA technique providing the prospect for direct measurement of these effects. In addition, REA has the potential to be applied in logistically difficult situations, such as on aircraft (Delon et al., 2000; Zhu et al., 1999) or urban flux towers.

Measurements of ammonia are hampered by the fact that the $\mathrm{NH}_{3}$ molecule quickly adheres to surfaces of different kinds. Especially wet surfaces in inlet-tubes, sample cells etc. can be a sink or, when a wet layer evaporates, a source of $\mathrm{NH}_{3}$. The high solubility of $\mathrm{NH}_{3}$ in water is related to the high polarity of the $\mathrm{NH}_{3}$ molecule. The amount of $\mathrm{NH}_{3}$ that can dissolve in water is further increased because $\mathrm{NH}_{3}$ reacts into $\mathrm{NH}^{4+}$. Until now, chemical adsorption techniques have therefore been most often used to determine atmospheric $\mathrm{NH}_{3}$ concentrations for flux measurements, with the most advanced being continuous wet-denuder methods (Kruit et al., 2007; Neftel et al., 1998; Blatter et al., 1993; Wyers et al., 1993). The time response of these chemical systems is improving, but it is unlikely that it will become sufficient to enable EC measurements. However, the sampling frequency required for REA is much less than for EC, with the result that several research teams have developed REA systems for $\mathrm{NH}_{3}$ that use either denuder filterpack combinations (Myles et al., 2007; Meyers et al., 2006; Ham and Baum, 2007) or denuder continuous wet chemical detection systems (Neftel et al., 1999; Erisman et al., 2001; Nemitz et al., 2001; Sørensen et al., 2003). Furthermore, inlet losses can significantly limit the response time for $\mathrm{EC} \mathrm{NH}_{3}$ systems resulting in uncertainties in flux estimates in the range of $0-40 \%$ that are comparable to those from REA (Whitehead et al., 2008; von Bobrutzki et al., 2009). The present study provides an inter-comparison based on these four REA implementations made within the context of the Braunschweig Integrated Experiment which was conducted as part of the EU GRAMINAE project. An overview of the experiment is given by Sutton et al. (2009a). Reference estimates for the time-course in $\mathrm{NH}_{3}$ concentrations and fluxes were provided by the AGM from a parallel inter-comparison of systems measuring vertical concentration profiles of $\mathrm{NH}_{3}$ (Milford et al., 2009). The inter-comparison presented here provides a basis to analyze the robustness of the REA approaches for continuous $\mathrm{NH}_{3}$ flux measurement, as well as to identify recommendations for further improvement, while the magnitude of the fluxes is discussed elsewhere (Milford et al., 2009; Sutton et al., 2009b).

\section{Material and methods}

\subsection{Micrometeorological theory}

In the EC approach the instantaneous fluctuation of the concentration $\left(\chi^{\prime}\right)$ of each eddy of air is related to the instantaneous vertical velocity ( $\left.w^{\prime}\right)$ of the eddy, such that, at its simplest within the atmospheric turbulent boundary layer over an extensive, uniform surface, the vertical flux $\left(F_{z}\right)$ at a location may be given as (see Lee et al., 2004 for details):

$F_{z}=\overline{\chi^{\prime} \cdot w^{\prime}}$

It is the requirement to sample each eddy of air contributing to the flux that leads to fast instrument response times being necessary for EC measurements. By contrast, the REA approach is based on the relationship between $F_{z}$ and the difference between the average trace gas concentration of upward and downward moving eddies of air. This requires fast response switching between air sampling of the up- and down-drafts, but only slow response ( $\sim 15 \mathrm{~min}$ to $2 \mathrm{~h})$ sampling of the trace gas concentrations, such that:

$F_{z}=\beta \sigma_{w}\left(\chi_{\uparrow}-\chi_{\downarrow}\right)$

where $\chi_{\uparrow}$ and $\chi_{\downarrow}$ are the average concentrations in the upand down-drafts, respectively, $\sigma_{w}$ is the standard deviation of the vertical wind velocity (derived from fast response measurements of $w^{\prime}$ ), and $\beta$ is an empirical dimensionless parameter which may be assumed to be a constant or estimated from measurements of fluxes of other scalars (Pattey et al., 1993). Values of $\beta$ coefficients are shown to vary between 0.40 to 0.63 (Milne et al., 1999). When applying the REA methodology, the $\beta$ factor can be estimated from turbulent measurements of temperature $(T)$ or momentum. In that case values of, for example, $T_{\uparrow}$ and $T_{\downarrow}$ are calculated in an on-line simulation. Then $\beta$ is calculated by analogy to Eq. (2) setting $F_{z}$ equal to the value of the sensible heat flux $(H)$ that is obtained from the covariance of $T^{\prime}$ and $w^{\prime}$.

The difference in concentration $\left(\chi_{\uparrow}-\chi_{\downarrow}\right)$ can be increased by introduction of a "deadband", such that air is not sampled when $w$ ' is near zero, with sampling only taking place when $\left|w^{\prime}\right|>D$. In case a constant $\beta$ coefficient is used in the flux calculation a correction should be applied to the empirical uncorrected $\beta$ factor $\left(\beta_{o}\right)$ to account for this deadband (after Pattey et al., 1993):

$\beta_{\text {corrected }}=\beta_{o}\left\{1-\beta_{o}\left[1-\exp \left(-b_{1} * D / \sigma_{w}\right)\right]\right\}$

With $D$ the deadband value, $\sigma_{w}$ the standard deviation of the vertical wind speed, $\beta_{o}=0.4$ and $b_{1}=1.9$. 

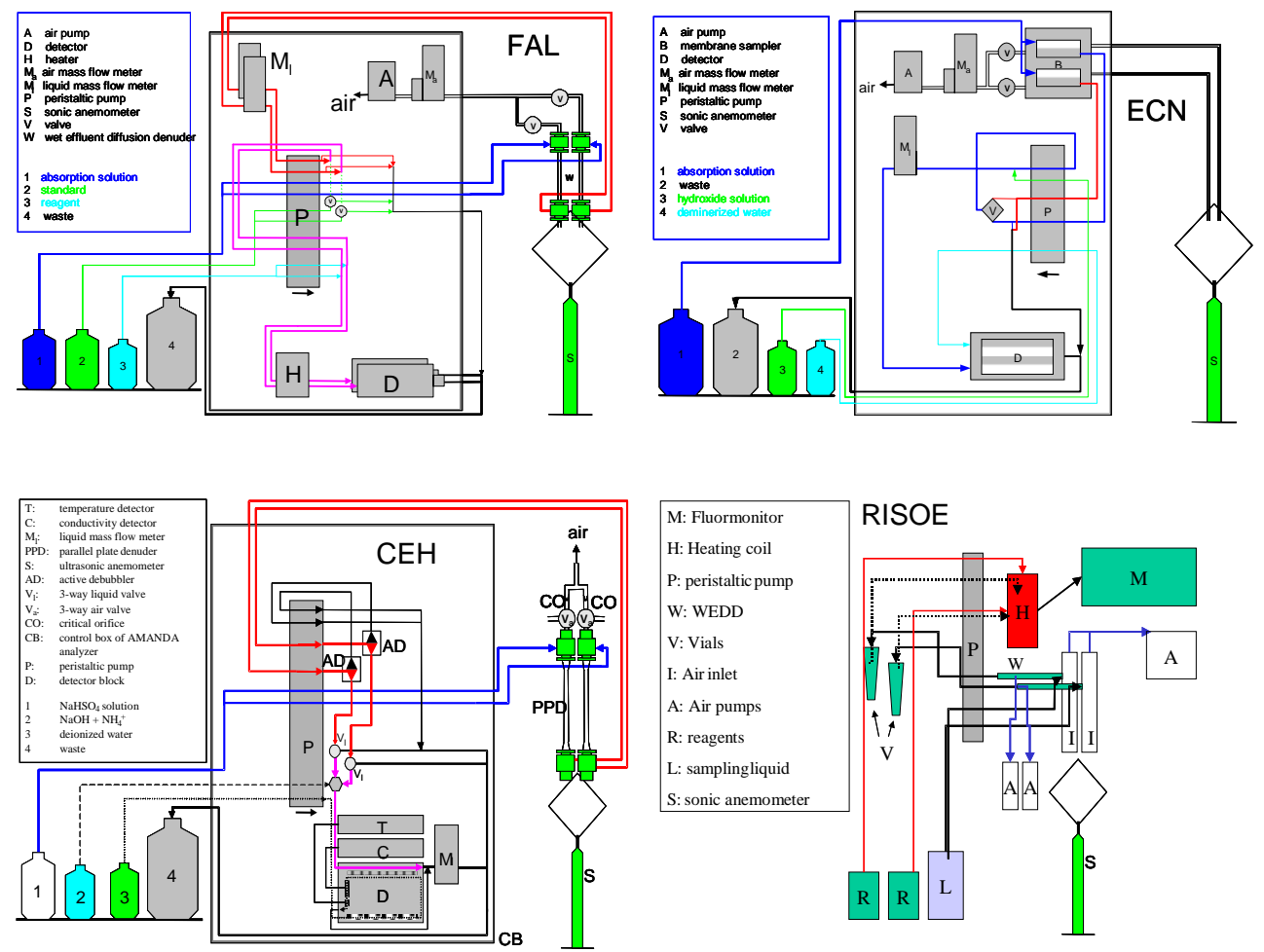

Fig. 1. Schematic diagrams of the four continuous relaxed eddy accumulation systems applied in the present intercomparison, as developed by: FAL (Neftel et al., 1999), ECN (Erisman et al., 2001), CEH/UMIST (Nemitz et al., 2001) and RISOE (Sørensen and Jensen, 2004).

\subsection{Measurement site}

The flux measurement site was an intensively managed experimental grassland of 12 ha situated on the grounds of the Federal Agricultural Research Centre (FAL), Braunschweig, Germany $\left(52^{\circ} 17^{\prime} 34^{\prime \prime} \mathrm{N}, 10^{\circ} 26^{\prime} 34^{\prime \prime} \mathrm{E}\right)$. Directly adjacent to the field are an experimental dairy farm of the FAL and a station of the German Weather Service (Deutscher Wetterdienst). The measurements reported here were made during the GRAMINAE Integrated Experiment (21 May-15 June 2000). Canopy height before the cut was $0.75 \mathrm{~m}$. The grass of the field was cut to $0.07 \mathrm{~m}$ canopy height on 29 May and the grass was removed on 31 May.

Fertilisation of the field with calcium ammonium nitrate took place on 5 June, being applied with a dose of $108 \mathrm{~kg} \mathrm{Nha}^{-1}$. The farmer irrigated the fields on $15-17$ May, before the experiment started. Weather conditions were mixed during the experiment, with in excess of $5 \mathrm{~mm}$ precipitation on 7 days, and maximum temperatures ranging from $14^{\circ} \mathrm{C}$ on 29 May to $31^{\circ} \mathrm{C}$ on 10 June. Mean daily windspeeds during the experiment ranged for $2.0-5.4 \mathrm{~m} \mathrm{~s}^{-1}$ (overall mean $3.4 \mathrm{~m} \mathrm{~s}^{-1}$ ), with mean daily relative humidity in the range $49-83 \%$.

A plan of the experimental site and other details of site conditions are provided by Sutton et al. (2009a). The REA systems were located near the centre of the experimental field at the main sampling site of the Integrated Experiment (Site 1 of Sutton et al., 2009a), where the fetch exceeded $150 \mathrm{~m}$ for wind sectors $20-180^{\circ}$ and $190-360^{\circ}$. A detailed assessment of vertical flux divergence at the site has been provided elsewhere, covering both storage and advection effects (Loubet et al., 2009; Milford et al., 2009), as well as the effects of chemical production and consumption in the surface layer (Nemitz et al., 2009a), with an overall synthesis of the different issues being provided by Sutton et al. (2009b).

\subsection{Measurement set-up}

The positions of the four REA systems spanned a total range of $15 \mathrm{~m}$ on a north-south line at Site 1 . Fetch conditions were similar for all samplers, with the exception of obstruction of fetch in the immediate vicinity by other equipment, for which account was taken in filtering the results. The schematic outlines of each of the four systems used and a summary of the differences and similarities of the systems are shown in Fig. 1 and Table 1, respectively. In all systems an ultra-sonic anemometer was used to determine $\sigma_{w}$ and drive the sample switching between $\chi_{\uparrow}$ and $\chi_{\downarrow}$. An evaluation of the friction velocity $\left(u_{*}\right)$ estimates and sensible heat fluxes $(H)$ derived by EC from each of these sonic-anemometer systems during the experiment and comparison with other parallel estimates has been provided by Nemitz al. (2009b). 
Table 1. System specifications of the different REA sampling methods.

\begin{tabular}{|c|c|c|c|c|}
\hline & CEH/UMIST & $\mathrm{ECN}$ & FAL* & RISOE \\
\hline Sampling Inlet & $\begin{array}{l}\text { Vertical } \\
\text { parallel-plate } \\
\text { denuders }\end{array}$ & $\begin{array}{l}\text { Membrane } \\
\text { chambers }\end{array}$ & Mini-WEDDs & $\begin{array}{l}\text { Stainless steel } \\
\text { inlets with } \\
\text { sub-sampling } \\
\text { to vertical wet } \\
\text { denuders }\end{array}$ \\
\hline $\begin{array}{l}\text { Measurement height above } \\
\text { ground }(\mathrm{m})\end{array}$ & 2.09 & 1.4 & 1.15 & 1.95 \\
\hline $\begin{array}{l}\text { Inlet Distance to ultra-sonic } \\
\text { anemometer (mm) }\end{array}$ & 300 & 50 & 50 & 500 \\
\hline $\begin{array}{l}\text { Ultra-sonic anemometer } \\
\text { type }\end{array}$ & $\begin{array}{l}\text { [2mm] Gill So- } \\
\text { lent 1012RA }\end{array}$ & $\begin{array}{l}\text { Gill Solent } \\
\text { 1012RA }\end{array}$ & $\begin{array}{l}\text { Gill Solent } \\
\text { 1012RA }\end{array}$ & Metek. \\
\hline Inlet system and length & $\begin{array}{l}\text { Separate inlets } \\
\text { for } \chi_{\uparrow} \text { and } \chi_{\downarrow} \text {, } \\
10 \mathrm{~mm}\end{array}$ & $\begin{array}{l}\text { Common inlet, } \\
150 \mathrm{~mm}\end{array}$ & $\begin{array}{l}\text { Separate inlets } \\
\text { for } \chi_{\uparrow} \text { and } \chi_{\downarrow} \text {, } \\
80 \mathrm{~mm}\end{array}$ & $\begin{array}{l}\text { Separate inlets } \\
\text { for } \chi_{\uparrow} \text { and } \chi_{\downarrow} \text {, } \\
500 \mathrm{~mm}\end{array}$ \\
\hline $\begin{array}{l}\text { Deadband value of } w \\
\left(\mathrm{~m} \mathrm{~s}^{-1}\right)\end{array}$ & 0.05 & 0.05 & none & $0.5 \sigma_{w}$ \\
\hline $\begin{array}{l}\text { Switch delay to account for } \\
\text { common inlet line }\end{array}$ & None & $1.5 \mathrm{~s}$ & None & None \\
\hline Air sampling rate $\left(1 \min ^{-1}\right)$ & 12 & 1.25 & 0.7 & $\begin{array}{l}10 \text { (denuders } \\
\text { subsample at } \\
\left.11 \mathrm{~min}^{-1}\right)\end{array}$ \\
\hline $\begin{array}{l}\text { Liquid flow rate to detector } \\
(\mathrm{ml} \mathrm{min}-1)\end{array}$ & 0.8 & - & 0.1 & - \\
\hline $\begin{array}{l}\text { Switching delay time for } \\
\text { liquid phase transport (min) }\end{array}$ & 14 & & 15 & \\
\hline Detector & $\begin{array}{l}\text { Selective mem- } \\
\text { brane diffusion } \\
\& \text { conductivity }\end{array}$ & $\begin{array}{l}\text { Selective mem- } \\
\text { brane diffusion } \\
\& \text { conductivity }\end{array}$ & $\begin{array}{l}\text { o- } \\
\text { phtalaldehyde } \\
\text { fluorescence }\end{array}$ & $\begin{array}{l}\text { o- } \\
\text { phtalaldehyde } \\
\text { fluorescence }\end{array}$ \\
\hline Detection limit $\left(\mathrm{ng} \mathrm{m}^{-3}\right)$ & 50 & 50 & 10 & 10 \\
\hline $\begin{array}{l}\text { Chemical detector response } \\
\text { time (min) }\end{array}$ & 2 & 5 & 5 & 5 \\
\hline $\begin{array}{l}\text { Chemical detector cycle of } \\
\text { up- and down air samples } \\
\text { (min, min) }\end{array}$ & $\begin{array}{l}\text { up } 2.5 \text {, down } \\
2.5 \text {; block- } \\
\text { averaged over } \\
3 \text { cycles to } \\
\text { provide } 15 \mathrm{~min} \\
\text { fluxes }\end{array}$ & up 10 , down 10 & up 10 , down 10 & $\begin{array}{l}\text { up } 7.5, \text { down } \\
7.5\end{array}$ \\
\hline Calibration type & $\begin{array}{l}\text { Aqueous stan- } \\
\text { dard }\left[\mathrm{NH}_{4}^{+}\right] \text {so- } \\
\text { lutions }\end{array}$ & $\begin{array}{l}\text { Aqueous stan- } \\
\text { dard }\left[\mathrm{NH}_{4}^{+}\right] \text {so- } \\
\text { lutions }\end{array}$ & $\begin{array}{l}\text { Aqueous stan- } \\
\text { dard }\left[\mathrm{NH}_{4}^{+}\right] \text {so- } \\
\text { lutions }\end{array}$ & $\begin{array}{l}\text { Aqueous stan- } \\
\text { dard }\left[\mathrm{NH}_{4}^{+}\right] \\
\text {solutions }\end{array}$ \\
\hline $\begin{array}{l}\text { Switching pattern for } \\
\text { up-down in reference sam- } \\
\text { pling mode }\end{array}$ & $2 \mathrm{~Hz}$ & W' time shift & $\begin{array}{l}\text { Random simi- } \\
\text { lar to } w\end{array}$ & $1 \mathrm{~Hz}$ \\
\hline $\begin{array}{l}\text { Cycle of sampling and ref- } \\
\text { erence sampling modes for } \\
\text { automatic bias correction }\end{array}$ & $7 \mathrm{~h}, 1 \mathrm{~h}$ & $7 \mathrm{~h}, 1 \mathrm{~h}$ & & \\
\hline Data acquisition software & $\begin{array}{l}\text { LabView } \\
\text { (National In- } \\
\text { struments, } \\
\text { Austin, TX) }\end{array}$ & $\begin{array}{l}\text { Delphi } \\
\text { (Borland) }\end{array}$ & $\begin{array}{l}\text { Lab view } \\
\text { (National In- } \\
\text { struments, } \\
\text { Austin, TX }\end{array}$ & $\begin{array}{l}\text { DAQ-SYS } \\
\text { (Risoe National } \\
\text { Laboratory) }\end{array}$ \\
\hline Manual performance check & $6 \mathrm{~h}$ & $12 \mathrm{~h}$ & $6 \mathrm{~h}$ & $6 \mathrm{~h}$ \\
\hline
\end{tabular}

* FAL-CH is now ART. 


\subsubsection{Inlet systems}

All four systems trap $\mathrm{NH}_{3}$ from the air in an aqueous solution. The CEH/UMIST (now CEH/UMAN) uses vertically mounted parallel plate denuders that are $\sim 300 \mathrm{~mm}$ long, $30 \mathrm{~mm}$ wide, with $4 \mathrm{~mm}$ between plates and chemically etched to improve the surface wetting. The denuders are wetted from the top of the denuder using a $3.6 \mathrm{nM}$ solution of $\mathrm{NaHSO}_{4}$ applied at a flow rate of $1.0 \mathrm{ml} \mathrm{min}{ }^{-1}$. The air is drawn into the bottom of each denuder during periods of + and $-w^{\prime}$, respectively, at a flow rate equivalent to $121 \mathrm{~min}^{-1}$ (Nemitz et al., 2001). A third denuder to sample the air concentration during the deadband is implemented, but may be deactivated.

The RISOE system has a stainless steel inlet system with a sample flow of $101 \mathrm{~min}^{-1}$ from which mini-WEDD (Wet Effluent Diffusion Denuder) denuders sub-sample with a flow of $11 \mathrm{~min}^{-1}$ (Sørensen and Jensen, 2004). The large flow in the stainless steel tubes is switched on and off to sample the up and down drafts. The air flow in the mini-WEDDs is continuous in order to maintain a laminar undisturbed flow. The FAL-CH (now ART) system uses mini-WEDD denuders sampling directly from the air. The denuders are operated vertically with the air flow in upward direction. The small size of the sampling system minimises flow distortion, the air flow rate for this system is $0.71 \mathrm{~min}^{-1}$ (Neftel et al., 1998). The ECN system has a $32 \mathrm{~mm}, 1 / 8$ inch diameter tube as inlet close to the sonic anemometer that splits into two sample tubes. The denuder is a membrane cell where the $\mathrm{NH}_{3}$ contained in an airflow of $1.251 \mathrm{~min}^{-1}$ diffuses across a PTFE membrane into $\mathrm{NaHSO}_{4}$ solution.

\subsubsection{Detection and response characteristics}

The CEH/UMIST and ECN systems use the same analytical principle as the AMANDA (Ammonia Measurement by Annular Denuder sampler with Analysis, ECN Netherlands) (Wyers et al., 1993). In this approach, $\mathrm{NaOH}$ is added to a continuous flow of an aqueous solution containing $\mathrm{NH}_{4}^{+}$ from $\mathrm{NH}_{3}$ in the air-sampling stream. The aqueous sample is passed over a hydrophobic PTFE membrane behind which is passed a counter-flow of deionised water. At the $\mathrm{pH}$ of the sample, $\mathrm{NH}_{\mathrm{x}}$ is present in solution as $\mathrm{NH}_{3(g)}$, which passes the membrane where it reverts to $\mathrm{NH}_{4}^{+}$. The $\mathrm{NH}_{4}^{+}$ions are then measured by electrical conductivity of the counter-flow solution. In the implementation of the CEH/UMIST system, both the air-flow and the liquid flow are a factor ten higher than the ECN system. The result is that resolution in concentration is similar, with a detection limit of about $50 \mathrm{ng} \mathrm{m}^{-3}$.

The FAL and RISOE systems use a fluorescence detection technique (Blatter et al., 1993; Sørensen et al., 1994). The analytical detection is based on the reaction between ophthaldialdehyde, a reducing agent and ammonia to produce a fluorescent compound (Rapsomanikis et al., 1988). With this system a detection limit of $10 \mathrm{ng} \mathrm{m}^{-3} \mathrm{NH}_{3}$ can be ob- tained. The fluorescence detector used in the FAL system is sufficiently stable to allow two separate detectors to be used to determine the concentrations simultaneously in the up- and down-channels. The CEH/UMIST, RISOE and ECN system use one common detector to obtain the concentration for both the up and the down sampling system, in order to avoid differences between individual detectors. In the case of the ECN system the concentration collected in the up sampler is measured in a $10 \mathrm{~min}$ period, followed by subsequent analysis of the sample obtained in the down sampler. The liquid sample of the latter is passed through a delayloop so both concentrations correspond to the same air mass. A similar approach is taken with the CEH/UMIST detection system, although, due to the higher flow rates, this has a faster response time compared with the ECN system, permitting a switching interval between up- and down-air samples of $2.5 \mathrm{~min}$. The liquid-phase transport time between the denuders and the detector of 14 min in the ECN system is taken into account when the concentrations are related to the turbulence. In the CEH/UMIST system the results of 3 switching cycles are block-averaged to provide 15-min fluxes. In the RISOE system the liquid from the two WEDDs sampled in two valves from where it is injected with a switching interval of $7.5 \mathrm{~min}$ into the fluorescence detector.

\subsubsection{Reference mode sampling}

In order to increase the sensitivity of the systems, the ECN, FAL and CEH/UMIST systems were operated in a reference sampling mode automatically for $0.5-1 \mathrm{~h}$ every 6 or $7 \mathrm{~h}$ to establish minor systematic biases between the two channels. The RISOE system was operated in a reference mode for $3 \mathrm{~h}$ at the end of the field campaign. In this reference mode, the air is sampled in a manner that is uncorrelated with vertical windspeed, so that the $\mathrm{NH}_{3}$ concentrations should be equal in both the up- and down-draught sampling inlets. These measurements provide useful information on the performance of the system. The difference found between the channels is used to correct for biases between the up- and down-draft sampling inlets.

For switching in reference mode, the CEH/UMIST system uses a fixed $2 \mathrm{~Hz}$ switching, opening and closing both the upand the down-inlet at the same time. The RISOE system uses a $1 \mathrm{~Hz}$ switching between up and down inlet. By contrast, the ECN system uses a delayed windspeed signal so that the random structure of sampling is maintained. The concentrations obtained with respectively up- and down-sampling systems are then corrected so both end up at the average of the two levels:

$$
\begin{aligned}
& \chi_{\text {corrected } \uparrow}=\chi_{\text {raw } \uparrow} *\left(\chi_{\text {ref } \downarrow}+\chi_{\text {ref } \uparrow}\right) /\left(2 \chi_{\text {ref } \uparrow}\right) \\
& \chi_{\text {corrected } \downarrow}=\chi_{\text {raw } \downarrow} *\left(\chi_{\text {ref } \downarrow}+\chi_{\text {ref } \uparrow}\right) /\left(2 \chi_{\operatorname{ref} \downarrow}\right)
\end{aligned}
$$

where $\chi_{\text {raw }}$ and $\chi_{\text {ref }}$ are the uncorrected concentration level and the concentration level obtained in reference mode for either the upward or down-inlet, respectively. 


\subsubsection{Use of a dead-band}

Since a very small deadband of $\left|w^{\prime}\right|<0.05 \mathrm{~m} \mathrm{~s}^{-1}$ was chosen for the CEH/UMIST system, only a small fraction of time was spent on the deadband and the concentration in this denuder tended to be below the detection limit. Thus the deadband denuder was deactivated for this study. Similar, the ECN system did not sample whenever $\left|w^{\prime}\right|<0.05 \mathrm{~m} \mathrm{~s}^{-1}$. By contrast, a "dynamic" deadband $\left(\left|w^{\prime}\right|<0.5 \sigma_{w}\right)$ was used by the RISOE system. The benefit of using a deadband as a function of $\sigma_{w}$ is that the $\beta$ coefficient found from the measurements does not need an empirical correction (Businger and Oncley, 1990). Furthermore this ensures that a sufficient amount of $\mathrm{NH}_{3}$ will always be sampled on the up- and downWEDDs.

The overall sampling cycle for the ECN system was $20 \mathrm{~min}$ and for the RISOE and CEH/UMIST system of $15 \mathrm{~min}$. The FAL system used no deadband and a $10 \mathrm{~min}$ cycle.

\subsubsection{Gradient reference}

The measurements by four $\mathrm{NH}_{3}$ vertical profile measurement systems were used with the AGM approach to obtain the concentration at $1 \mathrm{~m}$ height $(z)$ above the zero plane displacement $(d)$ and the reference flux (Milford et al., 2009). Values of $u_{*}$ for the AGM flux estimates were provided by the inter-comparison of Nemitz et al. (2009b). When comparing the best profile estimate of $\mathrm{NH}_{3}$ concentration with the REA estimates, the difference in height needs to be accounted for. Therefore the gradient estimates of $\left(z_{\text {ref }}\right)=1 \mathrm{~m}$ above $d$ and the gradient flux estimate were used to obtain height-corrected gradient-reference concentrations $\left(\chi_{\mathrm{AGM}}\right)$ at the heights of the various REA inlets:

$$
\chi_{\mathrm{AGM}}\left(z_{\mathrm{REA}}\right)=\chi(1 \mathrm{~m})-F_{z, \mathrm{AGM}}\left[R_{a}\left(z_{\mathrm{REA}}\right)-R_{a}(1 \mathrm{~m})\right]
$$

Here the term $R_{a}\left(z_{\mathrm{REA}}\right)-R_{a}(1 \mathrm{~m})$ represents the aerodynamic resistance $\left(R_{a}\right)$ between the level $z_{\text {ref }}$ and $z_{\text {REA }}$ for each REA system, with the $R_{a}$ values calculated from the consensus micrometeorological estimates of Nemitz et al. (2009b). The measured concentration levels obtained from each REA system were either obtained by simply averaging $\chi_{\uparrow}$ and $\chi_{\downarrow}$ or, for the CEH/UMIST dataset, as a weighted average of $\chi_{\uparrow}$ and $\chi_{\downarrow}$ using the actual time spent on sampling the up- and down-directions.

The comparison of the REA flux estimates and the AGM flux estimates was made in two stages. Firstly, the measured concentration values of the REA systems were compared with the AGM reference at the respective REA heights. The AGM reference flux estimates were then compared with the REA flux estimates that were normalized for the difference in REA and corresponding AGM concentrations. The purpose of this second stage was to distinguish methodological errors in the flux due to the REA approach, from those that were actually due to propagated errors arising from the basic deter- mination of $\chi\left(z_{\text {REA }}\right)$. Since the four gradient measurement systems were not consistent about the concentration levels on 3, 8, 9 and 10 June, alternative estimates of both the AGM flux and AGM concentration were proposed by Milford et al. (2009) and these are discussed in the following sections.

\section{Results}

\subsection{Data coverage}

The data coverage of the REA measurements is listed in Table 2. The CEH/UMIST system measured fluxes continuously from 25 May to 14 June, while the ECN and FAL systems were used for other purposes prior to cutting of the field. The FAL system unfortunately malfunctioned during a substantial part of the campaign. The ECN system stopped earlier than foreseen due to data acquisition problems. The table indicates the number of 15-min intervals for which measurements were foreseen (maximum) and the number of 15-min intervals with data. The data selection excluded data with windspeeds below $1 \mathrm{~m} \mathrm{~s}^{-1}$ and with wind directions outside the sector $180-350^{\circ}$. Especially when using a deadband, (CEH/UMIST, ECN and RISOE), the amount of air sampled during these periods is very small, leading to very low concentrations in the liquid flow and large uncertainties in the calculated concentration level.

\subsection{Micrometeorological estimates and deadband}

Comparison of $w$ ' data of the different ultra-sonic anemometers showed almost identical patterns. The CEH/UMIST and RISOE systems calculated the $\beta$ factor on-line using the measured temperature and sensible heat flux data. The same calculation of $\beta$ was made for the FAL system, but in a postprocessing of the data, rather than on-line. The ECN system used a deadband of $0.05 \mathrm{~m} \mathrm{~s}^{-1}$ and a correction was applied to the data according to Eq. (3).

\subsection{Reference sampling mode}

The data for the CEH/UMIST, FAL and RISOE systems were corrected using Eq. (4) with a linear interpolation of the reference sampling mode data before and after each $7 \mathrm{~h}$ sampling period. The ECN results showed significant scatter, when applying this correction using each interval between reference sampling data. In subsequent post-processing analysis, the ensemble of reference sampling measurements from the ECN system showed that the concentrations measured in the downward channel had a good linear relation to the concentrations in the upward channel $\left(r^{2}=0.9\right)$, but with a difference of $15 \%$. The ECN fluxes were therefore calculated using this fixed correction factor. This means that, while the relative difference was constant in the ECN system, it was variable in the other three systems. The difference in the ECN system was most likely due to a slight difference in collection 
Table 2. Data Coverage of the different REA sampling methods.

\begin{tabular}{lrrrr}
\hline & CEH/UMIST & FAL & RISOE & ECN \\
\hline $\begin{array}{l}\text { Start of measurements } \\
\text { (GMT) }\end{array}$ & $25 / 518: 45$ & $7 / 622: 00$ & $31 / 512: 30$ & $30 / 511: 20$ \\
$\begin{array}{l}\text { End of measurements } \\
\text { (GMT) }\end{array}$ & $14 / 616: 00$ & $10 / 622: 00$ & $7 / 604: 00$ & $8 / 605: 40$ \\
$\begin{array}{l}\text { Equipment operating } \\
\text { period (hours/no. of }\end{array}$ & $477 / 1909$ & $72 / 288$ & $160 / 638$ & $210 / 841$ \\
15 min estimates) & & & & \\
$\begin{array}{l}\text { Available flux estimates } \\
\text { (no. } 15 \text { min } \\
\text { estimates/\% of operat- } \\
\text { ing period) }\end{array}$ & $1160 / 61 \%$ & $27 / 9 \%$ & $304 / 48 \%$ & $380 / 45 \%$ \\
$\begin{array}{l}\text { Flux estimates passing } \\
\text { micromet criteria } * \text { (no. } \\
15 \text { min estimates/\% of } \\
\text { operating period) }\end{array}$ & $725 / 38 \%$ & $32 / 11 \%$ & $187 / 29 \%$ & $250 / 30 \%$ \\
\hline
\end{tabular}

* Micrometeorological criteria as defined by Nemitz et al.(2009b): $\mathrm{u}^{*}>0.2 \mathrm{~m} \mathrm{~s}^{1}$ and $|\mathrm{L}|>5 \mathrm{~m}$.

efficiency of the membrane samplers. This implies that the lower of the two concentrations in reference mode was underestimating the actual concentration.

\subsection{Comparison of ammonia concentration estimates}

The $\mathrm{NH}_{3}$ concentrations estimated by the four REA systems and the reference estimates from the profile measurements $\left(\chi_{\mathrm{AGM}}\right)$ ranged from 1 to $5 \mu \mathrm{g} \mathrm{NH}_{3} \mathrm{~m}^{-3}$, in the period before mowing and fertilizing (Fig. 2). Larger $\mathrm{NH}_{3}$ emissions following $\mathrm{N}$ fertilization resulted in peaks of up to $22 \mu \mathrm{g} \mathrm{NH}_{3} \mathrm{~m}^{-3}$, with largest values on the day of fertilization. The linear regressions of the REA concentration data versus the reference concentrations $\chi_{\text {AGM }}$ (Fig. 3) showed a good correlation with $r^{2}$ values ranging from 0.66 to 0.79 . The regression results of the comparison are summarized in Table 3, for all data.

For the small concentration ranges both the CEH/UMIST and ECN sensors gave similar levels compared with the gradient measurements, while the RISOE system tended to give lower concentrations. For the higher concentration range above $5 \mu \mathrm{g} \mathrm{NH}_{3} \mathrm{~m}^{-3}$, after the fertilisation event, all systems gave lower concentration levels compared with the gradient estimates. Overall the ECN system showed best agreement with the AGM concentrations with only $8 \%$ difference.

The $\chi_{\text {AGM }}$ in Figs. 2 and 3 is the best estimate, while the alternative estimate has lower concentration levels on the four days of 3, 8-10 June. On 3 June the ECN and CEH/UMIST data both show a good agreement with the "best estimate" concentration, while on 8,9 and 10 June both
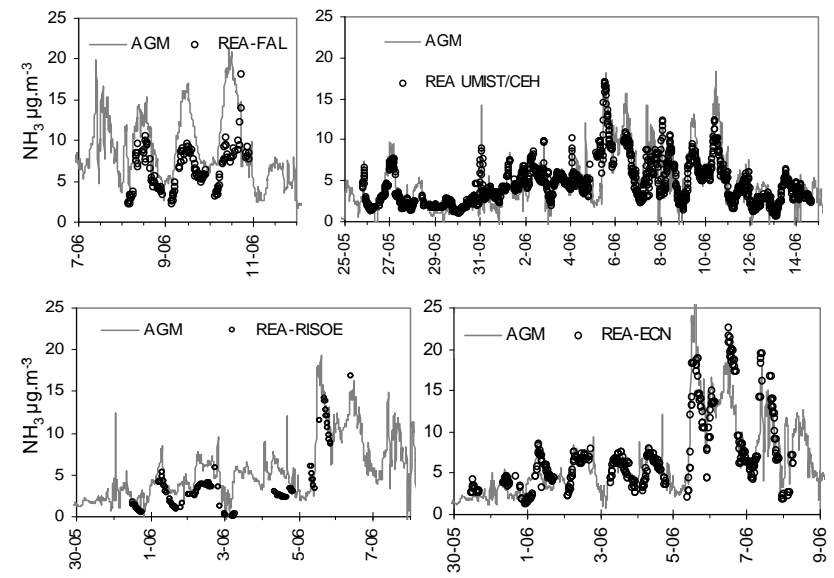

Fig. 2. Time series of the $\mathrm{NH}_{3}$ concentrations measured by the REA systems and the gradient reference concentration extrapolated to each REA inlet height as explained in the material and method section. All $\mathrm{y}$-axis in $\mu \mathrm{g} \mathrm{NH}_{3} \mathrm{~m}^{-3}$. Fertilisation occurs on 5 June, 06:00-07:00 a.m.

the CEH/UMIST system and the FAL system show concentration levels that are in better agreement with the alternative estimate.

\subsection{Comparison of the flux estimates}

The resulting fluxes as calculated for the four REA systems before and after fertilizing were compared with the "best 
Table 3. Results of the linear regression for the concentration measurements observed by the four REA systems versus the AGM results.

\begin{tabular}{|c|c|c|c|c|c|c|}
\hline \multirow[b]{2}{*}{ Comparison } & \multicolumn{3}{|c|}{$\begin{array}{c}\chi \mathrm{AGM}\left(\mu \mathrm{g} \mathrm{NH}_{3} \mathrm{~m}^{-3}\right) \\
\text { Linear Fit }\end{array}$} & \multicolumn{2}{|c|}{$\begin{array}{l}\chi \mathrm{AGM}\left(\mu \mathrm{g} \mathrm{NH}_{3} \mathrm{~m}^{-3}\right) \\
\text { Fit forced through zero }\end{array}$} & \multirow{2}{*}{$\begin{array}{r}\text { No. of } \\
\text { points } \\
n\end{array}$} \\
\hline & Slope & Intercept & $R^{2}$ & Slope & $R^{2}$ & \\
\hline CEH/UMIST & 0.69 & 1.3 & 0.74 & 0.87 & 0.66 & 1626 \\
\hline ECN & 0.93 & 0.45 & 0.79 & 0.97 & 0.79 & 415 \\
\hline FAL & 0.48 & 1.2 & 0.77 & 0.57 & 0.74 & 134 \\
\hline RISOE & 0.95 & -1.6 & 0.77 & 0.74 & 0.72 & 199 \\
\hline \multicolumn{7}{|c|}{ Using alternative AGM estimate ${ }^{\#}$} \\
\hline CEH/UMIST & 0.70 & 1.5 & 0.68 & 0.94 & 0.55 & \\
\hline FAL & 0.67 & 1.1 & 0.76 & 0.80 & 0.72 & \\
\hline
\end{tabular}

\# In the episode 3, 8, 9, 10 June the gradient data instruments are not unanimous so an "alternative gradient estimate" was proposed for these days.
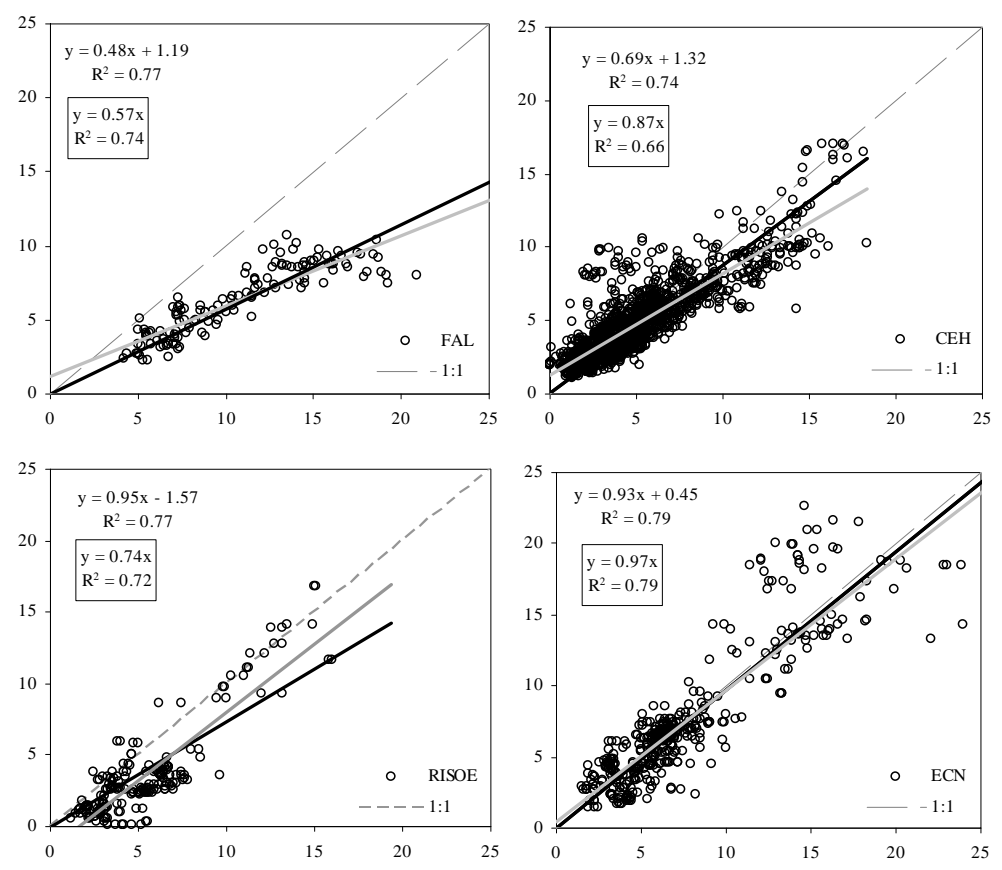

Fig. 3. Linear regression of the $\mathrm{NH}_{3}$ concentrations measured by the REA systems (y-axis) versus the AGM gradient reference concentration (x-axis) extrapolated to the each REA inlet height. All axes in $\mu \mathrm{g} \mathrm{NH}_{3} \mathrm{~m}^{-3}$. Fitting functions are shown both forced though zero (in the box) and with zero offset.

estimate" AGM reference data (Figs. 4 and 5). In Table 4 the results of linear regression for the uncorrected data versus the best estimate AGM data are shown in the first row. Over the whole period, the REA fluxes uncorrected for concentration are at least 50\% lower than the AGM "best estimate" flux. The best correlation is observed for the CEH/UMIST data set with $r^{2}=0.72$.

The REA flux corrected for the concentration difference $\left(\chi_{\mathrm{REA}} / \chi_{\mathrm{AGM}}\right)$ are also compared with the "best estimate" and the "alternative estimate" AGM fluxes (Table 4). The
CEH/UMIST and FAL REA fluxes compare better with the "alternative estimate" AGM flux. The $r^{2}$ value for the CEH/UMIST data are smaller than without the correction, suggesting that the correction with $\chi_{\mathrm{REA}} / \chi_{\mathrm{AGM}}$ introduces extra noise. The RISOE and ECN data only show a small change since the normalisation correction is small and these systems have no data on 8-10 June where the two AGM estimates are different.

The last part of Table 4 shows the effect of selection of the proper meteorological conditions, i.e. optimal fetch 
Table 4. Summary of the comparison of the REA fluxes with the "best estimate" and the alternative estimate fluxes obtained with the Aerodynamic Gradient Method (AGM). Intercepts are in $\mathrm{ng} \mathrm{NH}_{3} \mathrm{~m}^{-2} \mathrm{~s}^{-1}$.

\begin{tabular}{|c|c|c|c|c|c|c|c|c|}
\hline \multirow[t]{2}{*}{ Comparison with AGM flux } & \multicolumn{2}{|c|}{ CEH/UMIST } & \multicolumn{2}{|l|}{ FAL } & \multicolumn{2}{|c|}{ RISOE } & \multicolumn{2}{|l|}{ ECN } \\
\hline & Slope/Interc & $r^{2}$ & Slope/Interc & $r^{2}$ & Slope/Interc & $r^{2}$ & Slope/Interc & $R^{2}$ \\
\hline All data Best est. AGM & $0.52 / 43$ & 0.73 & $0.29 /-5$ & 0.30 & $0.50 / 1.3$ & 0.52 & $0.50 / 165$ & 0.48 \\
\hline \multicolumn{9}{|c|}{ All data. Fluxes corrected for $\chi_{\mathrm{REA}} / \chi_{\mathrm{AGM}^{*}}{ }^{*}$} \\
\hline Best e & $0.62 / 50$ & 0.65 & $0.41 / 169$ & 0.30 & $0.46 /-30$ & 0.45 & $0.49 / 145$ & 0.59 \\
\hline Alternative est. ${ }^{\#}$ AGM & $0.65 / 56$ & 0.65 & $0.69 / 78$ & 0.40 & $0.45 /-23$ & 0.49 & $0.50 / 145$ & 0.60 \\
\hline \multicolumn{9}{|c|}{ Selected data. $u(1 \mathrm{~m})>1 \mathrm{~m} \mathrm{~s}^{-1}, 180^{\circ}<W_{d}<350^{\circ}$} \\
\hline Best e & $0.68 / 33$ & 0.74 & $0.31 / 188$ & 0. & $0.33 /$ & 0.5 & $0.64 / 140$ & 0.72 \\
\hline Alternative AGN & $0.75 / 22$ & 0.80 & $0.5 / 86$ & 0.47 & $0.33 /-43$ & 0.52 & $0.65 / 141$ & 0.72 \\
\hline Before 5 June & $1.03 /-7$ & 0.55 & no data & & $0.56 /-98$ & 0.1 & $1.22 / 90$ & 0.28 \\
\hline After 5 June & $0.71 / 45$ & 0.79 & $0.5 / 86$ & 0.47 & $0.21 / 126^{* *}$ & 0.85 & $0.71 / 50$ & 0.81 \\
\hline
\end{tabular}

* For each 15 -min period the REA flux was multiplied by $\chi_{\mathrm{REA}} / \chi_{\mathrm{AGM}}$ to distinguish errors due to REA flux measurement from errors in concentration measurements.

** Only 9 data points available.

\# In the episode 3, 8, 9, 10 June the gradient data instruments are not unanimous so an "alternative gradient estimate" was proposed for these days.

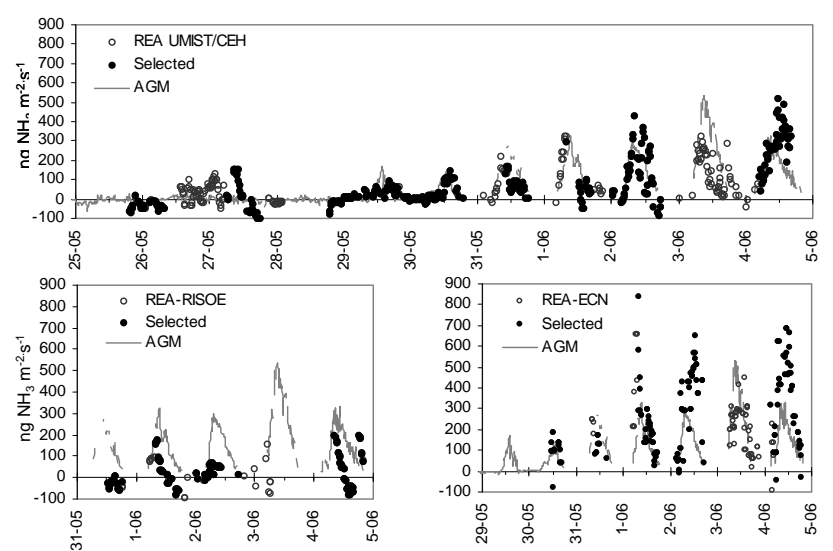

Fig. 4. Ammonia fluxes by the Relaxed Eddy Accumulation (REA) and the Aerodynamic Gradient Method (AGM) during the first part of the experiment. Cutting of the field took place 08:00-10:00 on 29 May. The REA fluxes are corrected by $\chi_{\mathrm{AGM}} / \chi_{\mathrm{REA}}$ for each 15 -min period. The RISOE and ECN systems started after cutting of the field.

conditions and $u>1 \mathrm{~m} \mathrm{~s}^{-1}$. In can be argued that data that does not meet the micrometeorological criteria should not be shown at all. However it is clear that this selection will preferentially remove fluxes at for example low windspeed i.e. at night. Table 4 therefore starts with the full data set and shows that while the selection seems important for one instrument it might be less sensitive for another (for example depending on the position on the field). The improvement for the CEH/UMIST and ECN data is most significant. The results for the FAL system do not improve, due to the small

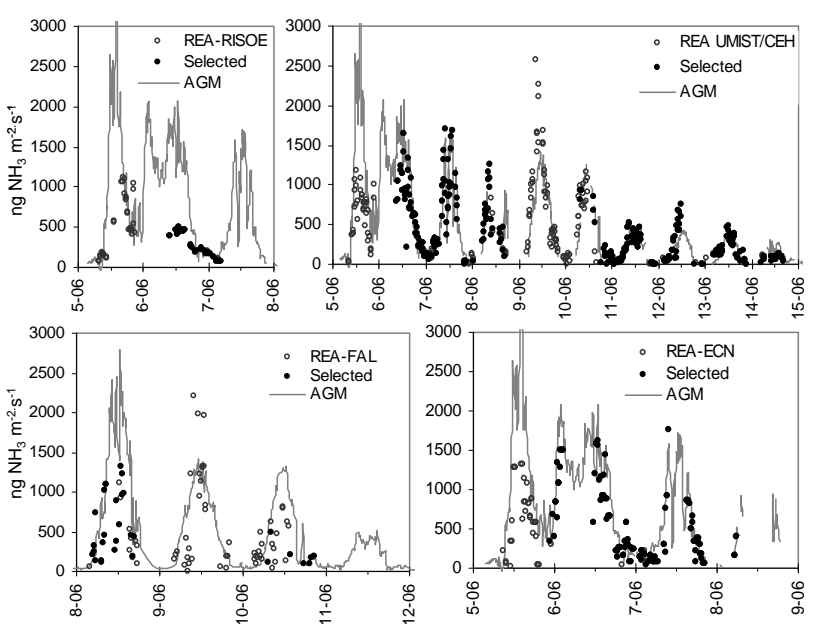

Fig. 5. Ammonia fluxes by the Relaxed Eddy Accumulation (REA) and the Aerodynamic Gradient Method (AGM) following $\mathrm{N}$ fertilization of the field 08:00-10:00 on 5 June. The REA fluxes are corrected $\chi_{\mathrm{AGM}} / \chi_{\mathrm{REA}}$ for each 15 -min period.

data set left after selection (33 data points). Finally, the comparison can be done either for the period before or after fertilisation on 5 June. The fit for the CEH/UMIST REA data versus the alternative AGM data shows a slope of 1.03 with $r^{2}=0.55$ for the first period. The overall underestimation of the REA fluxes as compared to the AGM flux is mainly explained by the underestimation during the post-fertilisation period, although during this period, the correlation is good as indicated by the large $r^{2}$. The FAL system only has postfertilisation data available, and the RISOE system has only 
9 data points during this period, with selected meteorological conditions. The ECN and the CEH/UMIST system give comparable fluxes after fertilisation, which were about $30 \%$ below the AGM estimate flux, with an $r^{2}$ of 0.8 . In the period before fertilisation the $\mathrm{ECN}$ system gives flux estimates that are $20 \%$ above the AGM estimates.

\section{Discussion}

\subsection{Estimation of the REA scaling factor $\beta$}

The $\beta$ factor estimated from $T$ and $H$ was, as expected, $\sim 0.6$ (Pattey et al., 1993; Gao, 1995). A systematic investigation by Ammann et al. (2002) showed that the $\beta$ factor increases weakly for stable conditions. However, a significant number of outliers and even negative values of $\beta$ were derived when $H$ was small and its direction poorly determined. Therefore most systems (CEH/UMIST, FAL \& RISOE) used only acceptable $\beta$ factors, for example in the range $0.1-1$, together with a fixed $\beta$ factor for periods for which the experimental value was unreasonable. For the CEH/UMIST dataset a comparison of 1162 flux values calculated both with a fixed $\beta$ factor and with measured (and acceptable) $\beta$ factor gives almost the same result. Linear regression between these two data sets showed an $r^{2}$ of 0.98 and a slope of 1.03 (the variable $\beta$ gives similar, though slightly larger fluxes on average than the fixed $\beta$ ). The ECN system used a theoretical $\beta$ factor (Eq. 3) throughout. Milne et al. (2001) have shown that the empirical value of $\beta$ can theoretically be derived from the combined frequency distribution of $w$ ' and $\chi^{\prime}$, if this follows a Gram-Charlier equation. This frequency distribution will depend on the spatial distribution of sources and sinks of the different tracers and may be different for highly reactive species such as $\mathrm{NH}_{3}$ or $\mathrm{O}_{3}$ and non-reactive species like $\mathrm{N}_{2} \mathrm{O}$ and $\mathrm{CO}_{2}$. Andreas et al. (1998) found $\beta$ to be 0.63 for momentum fluxes at near neutral conditions, but $\beta$ for scalars was only 0.52 .

Another possibility is that the $\beta$ factor used should actually be larger for reactive gases. In order to assess this, a set of $\mathrm{O}_{3}$ covariance flux measurements obtained during the Braunschweig experiment (Mészáros et al., 2009) was processed to estimate $\beta$. The average $\beta$ estimated over a day with 40 flux measurements was $\beta=0.62 \pm 0.09$ for $H$, and $\beta=0.58 \pm 0.06$ for $\mathrm{O}_{3}$ fluxes. The difference is thus not significant suggesting that reactive gases have the same $\beta$ as heat flux.

These small discrepancies need further assessment from a theoretical point of view, as the choice of the $\beta$ factor has a linear effect on the flux levels that are reported. However, the scale of these discrepancies is much smaller than those observed between the REA and AGM ammonia fluxes found in this study. This suggests that other reasons must account for the differences observed here.

\subsection{Comparison of measured ammonia concentrations and fluxes by the REA and AGM systems}

The concentration levels observed in the REA systems are generally less than the AGM values. For the FAL, RISOE and CEH/UMIST systems that use wet denuders, this can be caused by periods during which the denuders were not fully wet, therefore under-sampling. The ECN system with the membrane detector avoids this problem and indeed shows the best agreement in terms of average concentration levels. Incomplete wetting of the denuder walls was observed to be a problem with the CEH/UMIST system during episodes with high air temperatures (up to $>36^{\circ} \mathrm{C}$ ) experienced during the campaign. High temperatures also coincided with the periods of the largest $\mathrm{NH}_{3}$ emissions and thus largest air concentration. While the concentration ratios between the two denuders of the CEH/UMIST system were typically in the range 0.95 to 1.05 in the referencing periods (bias of $\pm 5 \%$ ), during some warm episodes, biases of more than $30 \%$ were observed, indicating that the capture efficiency of at least one denuder was reduced.

During the first half of the experiment, after correction for differences in concentration, the REA fluxes obtained with the CEH/UMIST system agree remarkably well with the AGM best estimate flux, within the range of variability found between individual gradient systems (Milford et al., 2009). The ECN system shows a higher noise level and shows flux levels that are $20 \%$ above the AGM estimates. This could be related to evaporation of dew on inlets in the early morning, as suggested by the higher emission peak of the ECN system in the morning of June 1 , for example. The CEH/UMIST system with a much larger air flow is less exposed to such problems. The RISOE fluxes seem to show an offset compared to the AGM fluxes, with deposition in the evening, or even during the day on 4 June. This could be due to a delay in the RISOE system caused by the automatic sampling in vials prior to injection into the analytical system.

After fertilising during the episode with high concentrations and large fluxes, all REA systems underestimate the flux by $30-50 \%$. Some days show an excellent agreement, for example on 6 June. The emission level on 5 June, on the fertilisation day (fertilised between 06:00 and 07:00 a.m.), is significantly underestimated. This can be due to the meteorological conditions which lie out of the selection for flux calculation (low windspeed from the east). For this period the correction for the concentration difference by REA/AGM is not sufficient to explain the difference between AGM and REA fluxes. This could be caused by an ineffective sampling of the REA systems, although the reference sampling mode should account for this effect. Crossover contamination between subsequent analyses of the up and down draft sample with a single detector could explain a systematic underestimation of the flux, since it will tend to bring the concentration levels closer together. Moreover, such a bias would not be detected by either the absolute concentration calibration or by 
the referencing mode. However, laboratory tests were performed on all systems with the detector alternating between two liquid solutions, and no such a problem was found.

Another problem may arise from the delay for the air flow to establish in the detectors after the air valve has been switched on. This delay, which can be as important as $0.5 \mathrm{~s}$ for system with large pressure drop (Pattey et al., 1993), causes a de-correlation between $w^{\prime}$ and $\chi$ ', which reduces the REA flux estimate. It would also reduce the REA average concentration by reducing the actual flow rate through the denuder, which is in agreement with the systematic underestimation of the REA concentrations.

Finally, the AGM flux estimates might actually show levels that are too high. Sutton et al. (2009b) show that while there is evidence for this in selected days (3, 8, 9, 10 June) using the "best estimates", the "alternative estimates" and results for other days give no evidence of over-estimation.

\subsection{Design features of the different REA systems}

The results show that the REA principle for $\mathrm{NH}_{3}$ flux measurement permits overall good performance, but the quality of the data still varies between implementations and in time. Improvement of the instrumental setup is still needed to obtain a robust continuous $\mathrm{NH}_{3}$ monitoring system.

\subsubsection{Sampling inlet and fast response switching}

There is always a time delay between the eddy occurring in the sonic anemometer and the opening of the valve that selects either up or downward sampling. This takes about 100 milliseconds depending on the valves used. The common inlet used in the ECN system enables a correction for this delay. This principle was demonstrated earlier for $\mathrm{CO}_{2}$ (Hensen et al., 1996). On the other hand in wet conditions, adsorption of $\mathrm{NH}_{4}^{+}$to the walls of the tube can occur, introducing adsorption/desorption effects which can smooth-out concentration differences. The trade-off between these two effects needs further evaluation in future campaigns.

Compared with the small inlet systems used in the FAL and ECN systems, the RISOE inlet system is large. In theory this might cause a flow disturbance. Therefore a test was performed comparing the spectral output of the ultra-sonic anemometer used in the REA configuration and a "standalone sonic anemometer". This exercise showed that there is no effect of the inlet systems for the relevant wind directions.

At increasing wind speeds and at decreasing measurement heights, a large fraction of the variance of $w$ is carried by high frequency eddies. This can be a problem when REA systems are operated too close to the ground at higher roughness since fast fluctuations in $w$ will cause the valves to open and close at very high frequencies $(1-10 \mathrm{~Hz})$ in order to measure the large variance.
A general recommendation for the inlet system is to make this as small as possible, because a smaller inlet can be positioned closer to the sonic without flow distortion. With the RISOE system, however, it was shown that even with a rather large inlet configuration, no disturbance on the sonic could be detected.

\subsubsection{Sampling height}

Requirements for high sampling rates and fast response inlets increase as the height above ground decreases. The spectral analysis of the data can be used to evaluate which part of the spectrum is contributing to vertical transport. This frequency depends on wind speed, roughness, atmospheric stability and measurement height (e.g. Eugster et al., 1995). The technical specifications of the system (for example the maximum switching frequency) that can be obtained with the valves therefore indirectly determine the minimum height at which the REA system will operate properly. Moreover, an upper limit to this height is set either by the fetch or by the minimum resolution of the concentration measurement. At large heights transport shifts to lower frequencies. So a longer averaging time is required to obtain representative sample for these frequencies. Longer averaging times will also reduce concentration differences between updrafts and downdrafts. The systems used here can be applied at heights above $1 \mathrm{~m}$, and below $30 \mathrm{~m}$. This will in general mean evaluation of fluxes in an area with a spatial scale of homogeneous fetch between 100 and $3000 \mathrm{~m}$ is possible.

\subsubsection{Chemical detection systems}

All the methods were sufficiently accurate to obtain the concentration differences between up and down samples. The reference sampling mode and the calibration tests showed that the systems worked according to specifications listed in Table 1. On three occasions an aqueous ammonia standard sample was provided blind to all systems. This showed agreement of the wet chemical analyses within $10 \%$.

\subsubsection{Use of the reference sampling mode}

The use of a reference sampling mode on a regular basis (e.g. for $1 \mathrm{~h}$ every $6-8 \mathrm{~h}$ ), during which the sampling is uncorrelated with the wind-speed, should provide equal concentrations in the up- and down-drafts sampling lines. The reference sampling method corrects for bias between the sampler inlets for up and down-drafts. It can, however, not correct for absolute errors in $\mathrm{NH}_{3}$ concentrations. These measurements provide also useful information on the performance of the system. Two methods were used: delayed wind-speed data set or synchronous switching. With the first method sampling conditions are identical to measurement conditions. However, cross-correlation spectra between $w$ and $c$ sometimes show secondary peaks. Potentially a shift could be selected 
that leads to a non-zero correlation and therefore still a difference in concentrations. Large changes in concentrations during the episode of reference sampling can pose a problem, especially for the systems that have a relatively large response time (RISOE and ECN system). Correction of the measurement data by scaling up and down concentrations, so that reference sampling concentrations in both channels are identical, works well most of the time.

\subsection{Potential for measurement of $\mathrm{NH}_{3}$ flux divergence using REA}

As noted in the introduction, one of the interests in developing REA systems to measure vertical fluxes of $\mathrm{NH}_{3}$ is that it allows flux measurement at one height. As a consequence, it becomes possible in principle to deploy several REA systems at different heights to measure divergence in the vertical flux, either due to local advection sources or chemical production/consumption in the surface layer. Nemitz et al. (2009a) demonstrate that $\mathrm{NH}_{3}$ emissions following fertilization lead to formation of particulate $\mathrm{NH}_{4}^{+}$, and correspondingly a consumption of $\mathrm{NH}_{3}$ in the air within and above the canopy. While the effect on particulate $\mathrm{NH}_{4}^{+}$dynamics is very large, $\mathrm{NH}_{3}$ gradients are the driving potential so that the relative effect on $\mathrm{NH}_{3}$ fluxes is rather small. Nemitz et al. (2009a) estimate that during daytime conditions in the days after fertilization (5-10 June) about $2 \%$ of the ground $\mathrm{NH}_{3}$ flux $\left(F_{z}\left(z_{o}\right)\right)$ would be lost to $\mathrm{NH}_{4}^{+}$aerosol by a height of $2 \mathrm{~m}$. Due to the large $\mathrm{NH}_{3}$ concentrations close to the surface most of this conversion is estimated to happen close to the ground $(<0.5 \mathrm{~m})$. Between $0.5 \mathrm{~m}$ and $2 \mathrm{~m}$ the effect is minor $(<1 \%)$, while above $2 \mathrm{~m}$ volatile $\mathrm{NH}_{4}^{+}$aerosol species $\left(\mathrm{NH}_{4} \mathrm{NO}_{3}, \mathrm{NH}_{4} \mathrm{Cl}\right)$ are more likely to re-evaporate. The magnitude of these effects is below the resolution in the REA systems when they perform best: the differences between the REA systems are larger, showing that further improvements are needed before REA can be applied as a robust tool for assessment of vertical flux divergence due to chemical production/consumption at the rates observed in this experiment.

There is a greater potential to apply REA to determine vertical flux divergence due to advection $\left(\Delta F_{z}\right.$,adv $)$. Loubet et al. (2009) analysed advection errors during the GRAMINAE Integrated Experiment, accounting for both advection from a local farm and advection caused by emissions from the field itself. For the REA sampling position (Site 1) in the middle of a large field, $\Delta F_{z \text {,adv }}$ at $1 \mathrm{~m}$ was in general from $+50 \mathrm{ng} \mathrm{NH}_{3} \mathrm{~m}^{-2} \mathrm{~s}^{-1}$ (advection dominated by the farm, prior to cutting of the field), to $-50 \mathrm{ng} \mathrm{NH}_{3} \mathrm{~m}^{-2} \mathrm{~s}^{-1}$ (advection dominated by the field following cutting and fertilization). The errors at the sampling heights of the REA systems $(\sim 2 \mathrm{~m})$ would be approximately double these values. Following cutting, the errors mostly represent $<5 \%$ of the emission fluxes and are not resolvable by the current REA implementations. However, the errors prior to cutting are of the same magnitude as the fluxes, indicating the potential for measurement of $\Delta F_{z, \text { adv }}$.

\section{Conclusions and recommendations}

Overall, the conclusion of this inter-comparison is that REA measurements for $\mathrm{NH}_{3}$ fluxes are possible, but they require substantial care in running the analytical equipment. For monitoring $\mathrm{NH}_{3}$ fluxes over the long-term (e.g. continuous operation over many months), these prototype systems are not yet sufficiently robust. Further attention is therefore needed to develop the methods for robust-automated operation. The wet chemical techniques will never be fast enough to enable full eddy covariance measurements of $\mathrm{NH}_{3}$. Optical techniques for $\mathrm{NH}_{3}$ detection are improving and flux measurement are becoming possible (Whitehead et al., 2008; Fischer and Littlejohn, 2007; Emmeneger, 2004). The accuracy of these systems is now sufficient to detect larger emission fluxes and the detection of deposition fluxes could become possible over the next years. Where the wet chemical systems make use of the adsorptive behaviour of the $\mathrm{NH}_{3}$ molecule and it's affinity with water this is an important problem for any closed path optical system. Open path optical systems that can evaluate $\mathrm{NH}_{3}$ with enough sensitivity do not have inlet problems but need sufficient pathlength and can therefore only detect larger eddies. So the wet chemical REA approach therefore remains a useful option as a research tool for intensive flux measurement over periods of days and weeks. In principle, it is attractive as a means to determine divergence in the vertical $\mathrm{NH}_{3}$ flux due to advection or chemical production/consumption. In practice, however, the scale of flux divergence due to chemistry (e.g. 10\%) is smaller than that which can currently be resolved, within the practical height restrictions of REA measurements. Advection errors due to emissions from the field itself are similarly too small to determine. By contrast, advection errors from nearby farm sources may be detectable through the application of REA measurements at several heights.

Acknowledgements. The work presented here was partly funded by the EU GRAMINAE Project (ENV4-CT98-0722) and the NitroEurope IP. For the experimental work for ECN we acknowledge the colleagues Julio Mosquera and Piet Jongejan. Additional support for this work was received from EU MEAD Project ENV4 (RISOE), the UK Department for Environment, Food and Rural Affairs (DEFRA), the UK Natural Environment Research Council (NERC) and the ministry of EZ and VROM (NL). NinE and COST 729 are acknowledged for travel funds. We are grateful for the experimental field site and facilities provided by U. Daemmgen of the FAL, Braunschweig.

Edited by: J. K. Schjoerring 


\section{References}

Andreas, E. L., Hill, A. J., Gosz, J. R., Moore, D. I., Otto, W. D., and Sarma, A. D.: Stability dependence of the eddy-accumulation coefficients for momentum and scalars, Bound.-Lay. Meteorol., 86, 409-420, 1998.

Ammann, C. and Meixner, F. :, Stability dependence of the relaxed eddy accumulation coefficient for various scalar quantities, J. Geophys. Res., 107(D8), 4071, doi:10.1029/2001JD000649, 2002.

Businger, J. A. and Oncley, S. P.: Flux Measurements with Conditional Sampling, J. Atmos. Ocean. Tech., 7(2), 349-352, 1990.

Blatter, A., Neftel, A., Dasgupta, P. K., and Simon P. K.: A combined wet effluent denuder and mist chamber system for deposition measurements of $\mathrm{NH}_{3}, \mathrm{NH}_{4}^{+}, \mathrm{HNO}_{3}$ and $\mathrm{NO}_{3}^{-}$. Presented at the $6^{\text {th }}$ European Symposium of Physico-Chemical behavior of atmospheric Pollutants, Varese, Italy, 1993.

Delon, C., Druilhet, A., Delmas, R., and Greenberg, J.: Aircraft assessment of trace compound fluxes in the atmosphere with Relaxed Eddy Accumulation: Sensitivity to the conditions of selection, J. Geophys. Res., 105(D16), 20461-20472, 2000.

Erisman, J. W., Otjes, R., Hensen, A., Jongejan, P., van den Bulk, P., Khlystov, A., Möls, H., and Slanina, S.: Instrument development and application in studies and monitoring of ambient ammonia, Atmos. Environ., 35, 1913-1922, 2001.

Emmeneger, L., Mohn, J., and Sig, M.: Measurement of ammonia emissions using various techniques in a comparative tunnel study, Int. J. Environ. Pollut., 22, 326-341, 2004.

Eugster, W. and Senn, W.: A Cospectral Correction Model for Measurement of Turbulent $\mathrm{NO}_{2}$ Flux, Bound.-Lay. Meteorol., 74(4), 321-340, 1995.

Famulari, D., Fowler, D., Hargreaves, K., Milford, C., Sutton M. A., Nemitz, E., and Weston, K.: Measuring eddy-covariance fluxes of ammonia using tunable diode laser absorption spectroscopy, Water AirSoil Pollut., 4(6), 151-158, 2004.

Fehsenfeld, F. C., Huey, L. G., Leibrock, E., Dissly, R., Williams, E., Ryerson, T. B., Norton, R., Sueper, D. T., and Hartsell, B.: Results from an informal intercomparison of ammonia measurement techniques, J. Geophys. Res., 107(D24), 4812, doi:10.1029/2001JD001327, 2002.

Fischer, M. L. and Littlejohn, D.: Ammonia at Blodgett Forest, Sierra Nevada, USA, Atmos. Chem. Phys. Discuss., 7, 1413914169, 2007, http://www.atmos-chem-phys-discuss.net/7/14139/2007/.

Gao, W.: The vertical change of coefficient $b$ used in the relaxed eddy accumulation method for flux measurements above and within a forest canopy, Atmos. Environ., 29(17), 2339-2347, 1995.

Ham, J. M. and Baum, J. M.: Measuring Ammonia Fluxes from Cattle Feedlots using Time-Averaged Relaxed Eddy Accumulation. International Symp. on Air Quality and Waste Management for Agriculture, 16-19 September 2007, Broomfield, Colorado, 2007.

Hensen, A., Vermeulen, A. T., Wyers, G. P., and Zhang, Y.: Eddy correlation and relaxed eddy accumulation measurements of $\mathrm{CO}_{2}$ fluxes over grassland, Phys. Chem. Earth, 21(5-6), 383388, 1996.

Kormann, R. and Meixner, F. X.: An analytical footprint model for nonneutral stratification, Bound.-Lay. Meteorol., 99, 207-224,
2001.

Kruit Wichink, R. J., van Pul, W. A. J., Otjes, R. P., Hofschreuder, P., Jacobs, A. F. G., and Holtslag A. A. M.: Ammonia fluxes and derived canopy compensation points over non-fertilized agricultural grassland in The Netherlands using the new gradient ammonia*high accuracy*monitor (GRAHAM), Atmos. Environ., 41, 1271-1287, 2007.

Lee, X., Massman, W., Law, B. (Eds.): Handbook of Micrometeorology. A Guide for Surface Flux Measurement and Analysis. Series: Atmospheric and Oceanographic Sciences Library, Vol. 29, XIV, 250 pp., 2004.

Loubet, B., Milford, C., Sutton, M. A., and Cellier, P.: Investigation of the interaction between sources and sinks of atmospheric ammonia in an upland landscape using a simplified dispersionexchange model, J. Geophys. Res., 106(D20), 24183-24196, 2001.

Loubet, B., Milford, C., Hensen, A., Daemmgen, U., Erisman, J.W., Cellier, P., and Sutton, M. A.: Advection of $\mathrm{NH}_{3}$ over a pasture field and its effect on gradient flux measurements, Biogeosciences, 6, 1295-1309, 2009,

http://www.biogeosciences.net/6/1295/2009/.

Mészáros, R., Horváth, L., Weidinger, T., Neftel, A., Nemitz, E., Dämmgen, U., Cellier, P., and Loubet, B.: Measurement and modelling ozone fluxes over a cut and fertilized grassland, Biogeosciences, 6, 1987-1999, 2009, http://www.biogeosciences.net/6/1987/2009/.

Meyers, T. P., Luke, W. T., and Meisinger, J. J.: Fluxes of ammonia and sulfate over maize using relaxed eddy accumulation, Agr. Forest Meteorol., 136, 203-213, 2006.

Milford, C., Theobald, M. R., Nemitz, E., Hargreaves, K. J., Horvath, L., Raso, J., Dämmgen, U., Neftel, A., Jones, S. K., Hensen, A., Loubet, B., Cellier, P., and Sutton, M. A.: Ammonia fluxes in relation to cutting and fertilization of an intensively managed grassland derived from an inter-comparison of gradient measurements, Biogeosciences, 6, 819-834, 2009, http://www.biogeosciences.net/6/819/2009/.

Milne, R., Beverland, I. J., Hargreaves, K., and Moncrieff, J. B.: Variation of the beta coefficient in the relaxed eddy accumulation method, Bound.-Lay. Meteorol., 93(2), 211-225, 1999.

Milne, R., Mennim, A., and Hargreaves K.: The value of the $\beta$ coefficient in the relaxed eddy accumulation method in terms of fourth order moments, Bound.-Lay. Meteorol.,101(3), 359-373, 2001.

Moncrieff, J. B., Massheder, J. M., de Bruin, H., Elbers, J., Friborg, T., Heusinkveld, B., Kabat, P., Scott, S., Sogaard, H., and Verhoef, A.: A system to measure surface fluxes of momentum, sensible heat, water vapour and carbon dioxide, J. Hydrol., 188189, 589-611, 1997.

Myles, L., Meyers, T. P., and Robinson, L.: Relaxed eddy accumulation measurements of ammonia, nitric acid, sulfur dioxide and particulate sulfate dry deposition near Tampa, FL, USA., Environ. Res. Lett., 2 034004, doi:10.1088/1748-9326/2/3/034004, 2007.

Neftel, A., Blatter, A., Gut, A., Hoegger, D., Meixner, F. X., Ammann, C., and Nathaus, F. J.: $\mathrm{NH}_{3}$ soil and soil surface gas measurements in a triticale wheat field, Atmos. Environ. (Ammonia Special Issue), 32 (3), 499-506, 1998.

Neftel, A., Blatter, A., Otjes, R., Erisman, J. W., and Hansen, A.: State of the art REA $\mathrm{NH}_{3}$ flux measurements, in: Proc. 10th Ni- 
trogen Workshop, Copenhagen, August 1999, II.49. Royal Veterinary and Agricultural University, Copenhagen, 1999.

Nemitz, E., Flynn, M., Williams, P. I., Milford, C., Theobald, M. R., Blatter, A., Gallagher, M. W., and Sutton, M. A.: A Relaxed Eddy Accumulation system for the automated measurement of atmospheric ammonia fluxes, Water Air Soil Pollut., 1(50-6), 189-202, 2001.

Nemitz, E., Dorsey, J. R., Flynn, M. J., Gallagher, M. W., Hensen, A., Erisman, J.-W., Owen, S. M., Dämmgen, U., and Sutton, M. A.: Aerosol fluxes and particle growth above managed grassland, Biogeosciences, 6, 1627-1645, 2009a, http://www.biogeosciences.net/6/1627/2009/.

Nemitz, E., Hargreaves, K. J., Neftel, A., Loubet, B., Cellier, P., Dorsey, J. R., Flynn, M., Hensen, A., Weidinger, T., Meszaros, R., Horvath, L., Dämmgen, U., Frühauf, C., Löpmeier, F. J., Gallagher, M. W., and Sutton, M. A.: Intercomparison and assessment of turbulent and physiological exchange parameters of grassland, Biogeosciences, 6, 1445-1466, 2009b, http://www.biogeosciences.net/6/1445/2009/.

Pattey, E., Desjardins, R. L., and Rochette, P.: Accuracy of the relaxed eddy-accumulation technique, evaluated using $\mathrm{CO}_{2}$ flux measurements, Bound.-Lay. Meteorol., 66, 341-355, 1993.

Pattey, E., Strachan, I. B., Desjardins, R. L., Edwards, G. C., Dow, D., and MacPherson, J. I.: Application of a tunable diode laser to the measurement of $\mathrm{CH}_{4}$ and $\mathrm{N}_{2} \mathrm{O}$ fluxes from field to landscape scale using several micrometeorological techniques, Agr. Forest Meteorol., 136, 222-236, 2006.

Rapsomanikis, S., Wake, M. T., Kitto, A.-M., and Harrison, R. M.: Analysis of atmospheric ammonia and particulate ammonium by a sensitive fluorescence method, Environ. Sci. Technol., 22, 948952, 1998

Shaw, W. J., Spicer, C. W, and Kenny, D. V.: Eddy correlation fluxes of trace gases using a tandem mass spectrometer, Atmos. Environ., 32, 2887-2898, 1998.

Sørensen, L. L., Granby, K., Nielsen, H., and Asman, W. A. H.: Diffusion scrubber technique used for measurements of atmospheric ammonia, Atmos. Environ., 28, 3637-3645, 1994.

Sørensen, L. L, Hertel, O., Ambelas Skjøth, C., Lund, M., and Pedersen, B.: Fluxes of ammonia in the coastal marine boundary layer, Atmos. Environ., 37, Suppl. 1, 167-177, 2003.

Sutton, M. A., Milford, C., Nemitz, E., Theobald, M. R., Hill, P. W., Fowler, D., Schjoerring, J. K., Mattsson, M. E., Nielsen, K. H., Husted, S., Erisman, J. W., Otjes, R., Hensen, A., Mosquera, J., Cellier, P., Loubet, B., David, M., Genermont, S., Neftel, A., Blatter, A., Herrmann, B., Jones, S. K., Horvath, L., Führer, E., Mantzanas, K., Koukoura, Z., Gallagher, M., Williams, P., Flynn, M., and Riedo, M.: Biosphere-atmosphere interactions of ammonia with grasslands: experimental strategy and results from a new European initiative, Plant Soil, 228(1), 131-145, 2001.
Sutton, M. A., Nemitz, E., Theobald, M. R., Milford, C., Dorsey, J. R., Gallagher, M. W., Hensen, A., Jongejan, P. A. C., Erisman, J. W., Mattsson, M., Schjoerring, J. K., Cellier, P., Loubet, B., Roche, R., Neftel, A., Hermann, B., Jones, S. K., Lehman, B. E., Horvath, L., Weidinger, T., Rajkai, K., Burkhardt, J., Löpmeier, F. J., and Daemmgen, U.: Dynamics of ammonia exchange with cut grassland: strategy and implementation of the GRAMINAE Integrated Experiment, Biogeosciences, 6, 309-331, 2009a, http://www.biogeosciences.net/6/309/2009/.

Sutton, M. A., Nemitz, E., Milford, C., Campbell, C., Erisman, J. W., Hensen, A., Cellier, P., David, M., Loubet, B., Personne, E., Schjoerring, J. K., Mattsson, M., Dorsey, J. R., Gallagher, M. W., Horvath, L., Weidinger, T., Meszaros, R., Dämmgen, U., Neftel, A., Herrmann, B., Lehman, B. E., Flechard, C., and Burkhardt, J.: Dynamics of ammonia exchange with cut grassland: synthesis of results and conclusions of the GRAMINAE Integrated Experiment, Biogeosciences Discuss., 6, 1121-1184, 2009b, http://www.biogeosciences-discuss.net/6/1121/2009/.

von Bobrutzki, K., Braban, C. F., Famulari, D., Jones, S. K., Blackall, T., Smith, T. E. L., Blom, M., Coe, H., Gallagher, M., Ghalaieny, M., McGillen, M. R., Percival, C. J., Whitehead, J. D., Ellis, R., Murphy, J., Mohacsi, A., Junninen, H., Pogany, A., Rantanen, S., Sutton, M. A., and Nemitz, E.: Field inter-comparison of eleven atmospheric ammonia measurement techniques, Atmos. Meas. Tech. Discuss., 2, 1783-1836, 2009,

http://www.atmos-meas-tech-discuss.net/2/1783/2009/.

Whitehead, J. D., Twigg, M., Famulari, D., Nemitz, E., Sutton, M. A., Gallagher, M. W., and Fowler, D.: Evaluation of Laser Absorption Spectroscopic Techniques for Eddy Covariance Flux Measurements of Ammonia, Environ. Sci. Technol., 42(6), 2041-2046, 2008.

Wyers, G. P., Otjes, R. P., and Slanina, J.: A continuous-flow denuder for the measurement of ambient concentrations and surface-exchange fluxes of ammonia, Atmos. Environ., 27A(13), 2085-2090, 1993.

Zhu, T., Wang, D., Desjardins, R. L., and Macpherson, J. I.: Aircraft-based volatile organic compounds flux measurements with relaxed eddy accumulation, Atmos. Environ., 33, 19691979, 1999.

Zhu, T., Pattey, E., and Desjardins, R. L.: Relaxed eddyaccumulation for measuring ammonia volatilization, Environ. Sci. Technol., 34(1), 199-203, 2000. 